\title{
Genotyping of a tri-allelic polymorphism by a novel melting curve assay in MTHFD1L: an association study of nonsyndromic Cleft in Ireland
}

\author{
Stefano Minguzzi ${ }^{1}$, Anne M Molloy ${ }^{2}$, Kirke Peadar ${ }^{3}$, James Mills ${ }^{4}$, John M Scott ${ }^{5}$, James Troendle ${ }^{4}$, Faith Pangilinan ${ }^{6}$,
} Lawrence Brody ${ }^{6}$ and Anne Parle-McDermott ${ }^{*}$

\begin{abstract}
Background: Polymorphisms within the MTHFD1L gene were previously associated with risk of neural tube defects in Ireland. We sought to test the most significant MTHFD1L polymorphisms for an association with risk of cleft in an Irish cohort. This required the development of a new melting curve assay to genotype the technically challenging MTHFD1L triallelic deletion/insertion polymorphism (rs3832406).

Methods: Melting curve analysis was used to genotype the MTHFD1L triallelic deletion/insertion polymorphism (rs3832406) and a Single Nucleotide Polymorphism rs17080476 in an Irish cohort consisting of 981 Irish case-parent trios and 1,008 controls. Tests for association with nonsyndromic cleft lip with or without cleft palate and cleft palate included case/control analysis, mother/control analysis and Transmission Disequilibrium Tests of case-parent trios.

Results: A successful melting curve genotyping assay was developed for the deletion/insertion polymorphism (rs3832406). The TDT analysis initially showed that the rs3832406 polymorphism was associated with isolated cleft lip with or without cleft palate. However, corrected p-values indicated that this association was not significant.

Conclusions: Melting Curve Analysis can be employed to successfully genotype challenging polymorphisms such as the MTHFD1L triallelic deletion/insertion polymorphism (DIP) reported here (rs3832406) and is a viable alternative to capillary electrophoresis. Corrected p-values indicate no association between MTHFD1L and risk of cleft in an Irish cohort.
\end{abstract}

\section{Background}

Cleft lip with or without cleft palate (CLP) and cleft palate only (CPO) are common birth defects of complex and heterogeneous aetiology. Previous studies suggest that folate deficiency before or during pregnancy can increase risk of clefting in the resulting offspring [1-4]. Folate supplementation in pregnancy has been shown to reduce the recurrence of CLP in families and to have a modest reduction in birth prevalence on a population basis [5]. Nevertheless this association is still controversial [6,7]. Numerous candidate gene association studies between clefts and folate related genes have shown mixed results and include methylenetetrahydrofolate reductase (MTHFR [Genbank:

\footnotetext{
* Correspondence: anne.parle-mcdermott@dcu.ie

'Nutritional Genomics Group, School of Biotechnology, Dublin City University, Dublin, Ireland

Full list of author information is available at the end of the article
}

NP_005948.3]) [4,8-16], methylenetetrahydrofolate dehydrogenase (NADP + dependent) (MTHFD1 [Genbank: NP_005947.3]) [1,16,17], 5,10-methenyltetrahydrofolate synthetase (MTHFS [Genbank: NP_001186689.1]) and methionine synthase (MTR [Genbank: NP_000245.2]) [4,17-19]. However, candidate gene studies to date have not considered MTHFD1L [Genbank: NP_001229696.1] in relation to nonsyndromic clefts. Environmental factors were reported for this cohort previously [16] and included data on the mother's medication use, folic acid exposure, alcohol and smoking. No interaction between genotype and these environmental factors were found in that study.

Based on its association with neural tube defects (NTDs) [20], and the previously detected association of its cytoplasmic homologue MTHFD1 in our cleft cohort, we considered the mitochondrial enzyme MTHFD1L to be a prime candidate for consideration for association 
with cleft. The relevance of this gene is increasing given its identification in genome wide association screens as being associated with coronary artery disease [21,22] and Alzheimer's disease [23]. Moreover a previous study has shown that MTHFD1L is upregulated in human colon adenocarcinoma [24]. The MTHFD1L gene encodes the mitochondrial C1-Tetrahydrofolate(THF) Synthase protein which has a monofunctional 10-formyl-THF synthetase activity while lacking the 5,10-methylene-THF dehydrogenase and 5,10-methenyl-THF cyclohydrolase activities typically found in the trifunctional cytoplasmic protein encoded by MTHFD1 [25]. It has been shown that the MTHFD $1 L$ gene produces 2 alternatively spliced mRNAs with the shorter transcript lacking synthetase activity [26]. Previously, we reported that the MTHFD1L rs3832406 DIP and numerous SNPs in linkage disequilibrium (LD) are associated with the risk of NTDs in the Irish population [20]. We proposed that the DIP polymorphism is the direct disease causing variant within the associated $\mathrm{LD}$ block by affecting alternative splicing of the gene [20].

In this study, we genotyped the MTHFD1L DIP rs3832406 and the most statistically significant NTDassociated SNP in the adjacent LD block i.e., rs17080476, in 981 Irish case-parent trios affected by CPL or CPO. We developed a melting curve method capable of genotyping deletion/insertion polymorphisms without the need for capillary electrophoresis.

\section{Methods \\ Subjects}

Buccal swab or blood samples were obtained at the Dublin Cleft Centre in Ireland as previously described [16] from subjects with cleft palate only (CPO) or cleft lip with or without cleft palate (CLP) along with their mothers and fathers. A total of 2,688 samples including 758 complete triads and 223 incomplete triads were collected for this study. Out of the total number of cleft cases this included 347 (33.8\%) isolated CPO cases plus an additional 108 (10.5\%) with multiple defects and 531 (51.7\%) isolated CLP cases plus an additional $42(4 \%)$ with multiple defects. All the cases of this study were non-syndromic. Multiple cases included children with one or multiple defects along with cleft. Chromosomal anomalies and other conditions (i.e. mother had diabetes or epilepsy or was exposed to potentially teratogenic drugs) were excluded. Control samples $(n=1,008)$ were collected from a population of 56,049 pregnant women attending the three main maternity hospitals in the Dublin area between 1986 and 1990 as previously described [16,27]. Written informed consent was obtained from all participants. Ethical approval was granted by the Research Ethics Committees of the Health Research Board of Ireland, the participating hospitals, and the Institutional Review Board at NIH.

\section{Genotyping}

Genomic DNA was extracted from blood or buccal swab collected samples using a QIAamp DNA Blood Mini Kit (Qiagen, UK). HybProbe melting curve assays were designed to genotype DIP rs3832406 and SNP rs17080476 on a LightCycler 480 Real Time PCR machine (Roche) and are described in more detail below. Genotyping quality was verified by repeat genotyping of at least $10 \%$ of samples with agreement rate of $>99 \%$ and overall success rate of $>99 \%$. In addition, $10 \%$ of the controls were genotyped by the HybProbe melting curve assays described here and compared to the assays used previously [20]. Comparison of control genotype calls gave a 95.7\% agreement for DIP rs3832406 and 99\% agreement for SNP rs17080476. All discrepant genotype calls for any sample were resolved by re-genotyping or were left out of the final analysis.

\section{SNP rs17080476 assay}

SNP rs17080476 reagents and analysis conditions are: Forward Primer 5'-GCAACTTTGTTTAGTATGAAAA TTTGAT-3' $(4 \mu \mathrm{M})$, reverse primer5' -TCTGTCTTCAC CCAGCC $(2 \mu \mathrm{M})$, anchor probe 5 '-Bodipy630/650AAGAGGGGAAAAAAAACCTTTCTCCATTATTCCTAPHO-3' $(0.4 \mu \mathrm{M})$, sensor probe 5'-ATTCATTTCTTTA CAGCAGTGGGATTATGAAA-Fluorescein 3' $(0.2 \mu \mathrm{M})$, pre-incubation 10 minutes at $95^{\circ} \mathrm{C}$, amplification 45 cycles of 15 seconds at $95^{\circ} \mathrm{C}, 15$ seconds at $56^{\circ} \mathrm{C}, 15$ seconds at $72^{\circ} \mathrm{C}$, melting curve 1 minute at $95^{\circ} \mathrm{C}, 2$ minutes at $50^{\circ} \mathrm{C}$, acquisition ramp up to $80^{\circ} \mathrm{C}\left(0.11^{\circ} \mathrm{C} / \mathrm{s}, 5\right.$ acquisitions per ${ }^{\circ} \mathrm{C}$.

\section{DIP rs3832406 assay}

DIP rs3832406 reagents and analysis conditions are: forward primer 5' -AAGCTTCCTGTTACCAC-3' $(4 \mu \mathrm{M})$, reverse primer 5'-AGGAGAATCACTTCAACC-3' $(2 \mu \mathrm{M})$, anchor probe: 5'-AGCCCCACGTTTGAATTTTATGTT TTTCCTAAAGT-Fluorescein-3' $(0.2 \mu \mathrm{M})$. Sensor probe: 5'BODIPY630/650-AGGGAAGATTATTATTATTATTAT TATTATTATTTTCTTTTTCAGACGGA-Phosphate-3' $(0.2 \mu \mathrm{M})$,pre-incubation 10 minutes at $95^{\circ} \mathrm{C}$, amplification 45 Cycles of 10 seconds at $95^{\circ} \mathrm{C}, 10$ seconds at $56^{\circ} \mathrm{C}, 10$ seconds at $72^{\circ} \mathrm{C}$, melting curve 10 seconds at $95^{\circ} \mathrm{C}, 1$ minute at $50^{\circ} \mathrm{C}$, acquisition ramp up to $70^{\circ} \mathrm{C}$ $\left(0.02^{\circ} \mathrm{C} / \mathrm{s}, 30\right.$ acquisitions per $\left.^{\circ} \mathrm{C}\right)$.

\section{Statistical methods}

Power calculations to detect an odds ratio of 1.5 assuming a dominant model for the case-control analyses were as follows: rs3832406 Allele 1 60\%, Allele 2 95\%, Allele 3 93\%; rs17080476 G 95\%. Assuming a recessive model: rs3832406 Allele 1 96\%, Allele 2 36\%, Allele 3 23\%; rs 17080476 G $34 \%$. Our primary analysis was carried out with isolated nonsyndromic cases of CLP and CPO and 
their parents. A secondary analysis was then carried out including nonsyndromic cleft cases with other defects. Hardy-Weinberg equilibrium (HWE) was tested within each subject class (case, mother, father and controls) for each polymorphism by chi-squared test. Associations with CLP and CPO were tested for each polymorphism in cases/controls and separately in mothers/controls by logistic regression and odds ratios using either a dominant or recessive genetic disease model. Triads (case, mother, and father) were used to perform the Transmission Disequilibrium Test (TDT) of Spielman et al. [28]. The TDT P-values were adjusted using permutational correction [29].

\section{Results and discussion}

Development of a novel assay to genotype DIP rs3832406 by Melting Curve Analysis

The MTHFD1L gene has received particular attention in recent years owing to its association with coronary artery

\section{A. Allele 1}

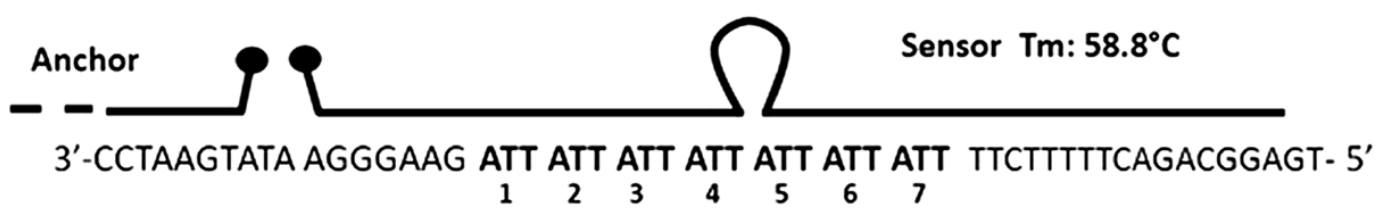

\section{B. Allele 2}

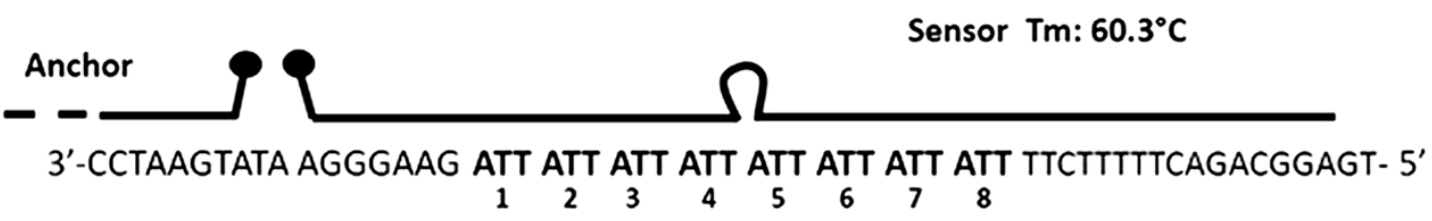

\section{Allele 3}

Sensor Tm: $63^{\circ} \mathrm{C}$
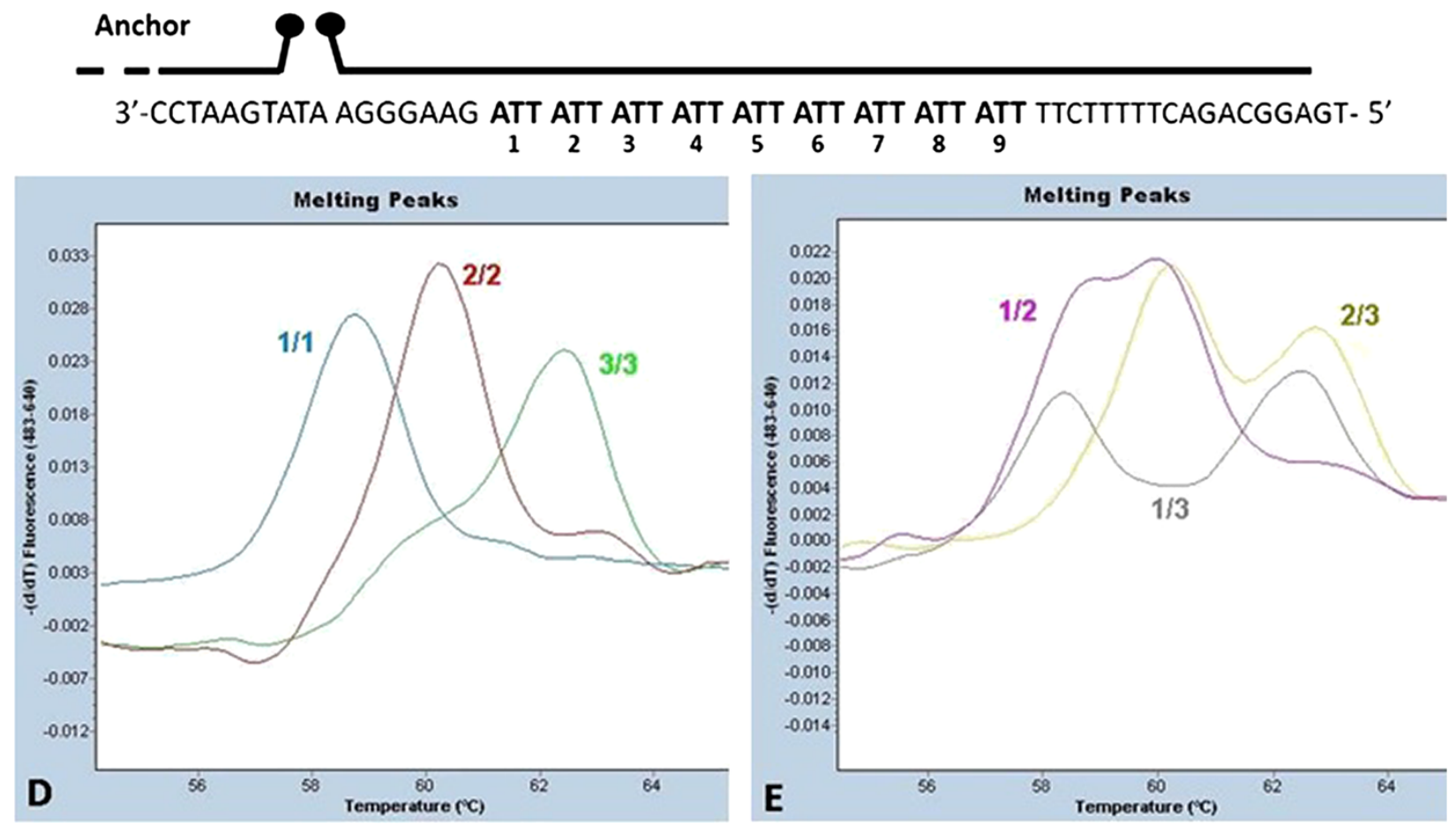

Figure 1 Modified Melting Curve Analysis for DIP rs3832406. The Sensor probe design for detection of all three alleles of DIP rs3832406 is shown. The Sensor probe is designed to perfectly match the complement of Allele 3. A. Sensor probe bound to Allele 1 has a Tm of $58.8^{\circ} \mathrm{C}$. B. Sensor probe bound to Allele 2 has a Tm of $60.3^{\circ} \mathrm{C}$. C. Sensor probe bound to Allele 3 has a Tm of $63^{\circ} \mathrm{C}$. D. Examples of homozygote melting peaks for each of the three alleles. E. Examples of heterozygote melting peaks for all three allele combinations. 
disease, Alzheimer's disease and NTDs. Our previous study, demonstrated that the MTHFD1L rs3832406 DIP is functional by impacting on alternative splicing efficiency [20]. We report a new modified melting curve assay to genotype this functionally relevant triallelic MTHFD1L polymorphism without the need for traditional capillary electrophoresis methods. A single assay which is able to distinguish 3 alleles contemporaneously was developed taking advantage of the GC-rich regions flanking the DIP (Figure 1). As described previously [20], this polymorphism is a repeated "ATT" sequence that has three common alleles, Allele $1\left(\mathrm{ATT}_{7}\right)$ Allele2
$\left(\mathrm{ATT}_{8}\right)$ and Allele $3\left(\mathrm{ATT}_{9}\right)$. A wide 50 -base sensor probe was designed to perfectly match Allele 3 with 9 ATT repeats and its flanking regions, producing a melting temperature $(\mathrm{Tm})$ of $63^{\circ} \mathrm{C}$ (Figure 1c). The same probe produces a 3-base mismatched bubble on Allele 2 and a 6-base mismatched bubble on Allele 1 causing a $\mathrm{Tm}$ of $60.3^{\circ} \mathrm{C}$ and $58.8^{\circ} \mathrm{C}$ respectively (Figure 1a-b). The probe pairing starts from the $\mathrm{GC}$-rich external regions allowing the formation of an internal mismatched bubble for Alleles 1 and 2. A slow acquisition ramp allowed melting peaks for each homozygote and heterozygote genotype to be distinguished (Figure 1d-e).

Table 1 MTHFD1L Genotyping Results in Triads (Cases, Mother and Fathers) and Controls for CLP and CPO (Isolated) or with Other Defects (Multiple)

\begin{tabular}{|c|c|c|c|c|c|c|c|c|c|c|c|c|c|c|}
\hline \multirow{3}{*}{$\begin{array}{l}\text { DIPrs3832406 } \\
\text { CLP }\end{array}$} & \multicolumn{6}{|c|}{ Isolated defects } & \multicolumn{6}{|c|}{ Multiple defects } & \multirow{2}{*}{\multicolumn{2}{|c|}{ Controls }} \\
\hline & \multicolumn{2}{|c|}{ Fathers } & \multicolumn{2}{|c|}{ Mothers } & \multicolumn{2}{|c|}{ Cases } & \multicolumn{2}{|c|}{ Fathers } & \multicolumn{2}{|c|}{ Mothers } & \multicolumn{2}{|c|}{ Cases } & & \\
\hline & $n$ & $\%$ & $n$ & $\%$ & $n$ & $\%$ & $n$ & $\%$ & $n$ & $\%$ & $n$ & $\%$ & $n$ & $\%$ \\
\hline 11 & 162 & 41.8 & 187 & 40.1 & 209 & 41.9 & 174 & 42.0 & 203 & 40.8 & 231 & 43.5 & 419 & 42.1 \\
\hline 12 & 102 & 26.3 & 128 & 27.5 & 149 & 29.9 & 116 & 28.0 & 140 & 28.1 & 163 & 30.7 & 267 & 26.8 \\
\hline 13 & 76 & 19.6 & 89 & 19.1 & 84 & 16.8 & 82 & 19.8 & 97 & 19.5 & 91 & 17.1 & 196 & 19.7 \\
\hline 22 & 18 & 4.6 & 24 & 5.2 & 18 & 3.6 & 18 & 4.3 & 24 & 4.8 & 18 & 3.4 & 40 & 4.0 \\
\hline 23 & 24 & 6.2 & 31 & 6.7 & 28 & 5.6 & 24 & 5.8 & 34 & 6.8 & 28 & 5.3 & 52 & 5.2 \\
\hline 33 & 6 & 1.5 & 7 & 1.5 & 11 & 2.2 & 6 & 1.4 & 7 & 1.4 & 11 & 2.1 & 21 & 2.1 \\
\hline Total & 388 & & 466 & & 499 & & 420 & & 505 & & 542 & & 995 & \\
\hline \multirow[t]{2}{*}{ CPO } & \multicolumn{2}{|c|}{ Fathers } & \multicolumn{2}{|c|}{ Mothers } & \multicolumn{2}{|c|}{ Cases } & \multicolumn{2}{|c|}{ Fathers } & \multicolumn{2}{|c|}{ Mothers } & \multicolumn{2}{|c|}{ Cases } & & \\
\hline & $n$ & $\%$ & $n$ & $\%$ & $n$ & $\%$ & $n$ & $\%$ & $n$ & $\%$ & $n$ & $\%$ & & \\
\hline 11 & 98 & 37.3 & 118 & 38.1 & 134 & 41.7 & 145 & 40.8 & 154 & 36.9 & 175 & 41.0 & & \\
\hline 12 & 78 & 29.7 & 82 & 26.5 & 88 & 27.4 & 97 & 27.3 & 110 & 26.4 & 118 & 27.6 & & \\
\hline 13 & 60 & 22.8 & 69 & 22.3 & 62 & 19.3 & 77 & 21.7 & 99 & 23.7 & 86 & 20.1 & & \\
\hline 22 & 8 & 3.0 & 12 & 3.9 & 7 & 2.2 & 8 & 2.3 & 18 & 4.3 & 9 & 2.1 & & \\
\hline 23 & 18 & 6.8 & 20 & 6.5 & 23 & 7.2 & 25 & 7.0 & 26 & 6.2 & 29 & 6.8 & & \\
\hline 33 & 1 & 0.4 & 9 & 2.9 & 7 & 2.2 & 3 & 0.8 & 10 & 2.4 & 10 & 2.3 & & \\
\hline Total & 263 & & 310 & & 321 & & 355 & & 417 & & 427 & & & \\
\hline SNPrs17080476 & & & Isolate & defects & & & & & Multip & defects & & & & \\
\hline \multirow[t]{2}{*}{ CLP } & \multicolumn{2}{|c|}{ Fathers } & \multicolumn{2}{|c|}{ Mothers } & \multicolumn{2}{|c|}{ Cases } & \multicolumn{2}{|c|}{ Fathers } & \multicolumn{2}{|c|}{ Mothers } & \multicolumn{2}{|c|}{ Cases } & \multicolumn{2}{|c|}{ Controls } \\
\hline & $n$ & $\%$ & $n$ & $\%$ & $n$ & $\%$ & $n$ & $\%$ & $n$ & $\%$ & $n$ & $\%$ & $n$ & $\%$ \\
\hline AA & 268 & 68.2 & 296 & 63.1 & 320 & 63.1 & 285 & 67.1 & 320 & 62.9 & 344 & 62.5 & 660 & 65.9 \\
\hline$A G$ & 110 & 28.0 & 160 & 34.1 & 170 & 33.5 & 124 & 29.2 & 176 & 34.6 & 188 & 34.2 & 308 & 30.8 \\
\hline GG & 15 & 3.8 & 13 & 2.8 & 17 & 3.4 & 16 & 3.8 & 13 & 2.6 & 18 & 3.3 & 33 & 3.3 \\
\hline Total & 393 & & 469 & & 507 & & 425 & & 509 & & 550 & & 1001 & \\
\hline & & & Isolate & defects & & & & & Multip & defects & & & & \\
\hline CPO & & & & & & & & & & & & & & \\
\hline & $n$ & $\%$ & $n$ & $\%$ & $n$ & $\%$ & $n$ & $\%$ & $n$ & $\%$ & $n$ & $\%$ & & \\
\hline AA & 173 & 65.5 & 205 & 65.7 & 214 & 65.6 & 234 & 65.9 & 274 & 65.6 & 288 & 66.8 & & \\
\hline$A G$ & 86 & 32.6 & 93 & 29.8 & 100 & 30.7 & 115 & 32.4 & 127 & 30.4 & 125 & 29.0 & & \\
\hline GG & 5 & 1.9 & 14 & 4.5 & 12 & 3.7 & 6 & 1.7 & 17 & 4.1 & 18 & 4.2 & & \\
\hline Total & 264 & & 312 & & 326 & & 355 & & 418 & & 431 & & & \\
\hline
\end{tabular}


DIP rs3832406, SNP rs17080476 and risk of CLP

We genotyped rs3832406 DIP and SNP rs17080476 in an Irish cleft cohort in a bid to test for association. The genotype frequencies of SNP rs17080476 and DIP rs3832406 in our CLP, CPO and control samples are shown in Table 1. Genotype distributions in all groups were in HWE. DIP rs3832406 showed an association with CLP case status based on TDT analysis (Table 2). The TDT analysis showed that Allele 1 is transmitted to the offspring $55.2 \%$ of times $(\mathrm{p}=0.037)$ in isolated CLP cases, indicating that this allele is associated with increased disease risk. The addition of multiple case families to this analysis enhances the statistical significance (56.1\% transmission, $\mathrm{p}=0.011$ ). Allele 3 has the lowest frequency and was passed to the offspring only $42.8 \%$ of times $(\mathrm{p}=0.035)$ in multiple CLP cases, appearing to have a protective role against the disease. However, correction of these significant $\mathrm{p}$-values using permutational adjustment resulted in loss of statistical significance. We did not observe statistical significance with SNP rs17080476 which shares a D' value of 0.61 with DIP rs3832406 and represented the most statistically compelling variant from this genomic region in our NTD study [20] (Table 2). The majority of other analyses performed showed no significant association with the risk of cleft (Table 3).

\section{Conclusion}

Our analysis shows no strong association between specific polymorphisms within the MTHFD1L gene and risk

Table 2 TDT analysis for DIP rs3832406 and SNP rs17080476 in all cleft sample

\begin{tabular}{|c|c|c|c|c|c|c|c|c|}
\hline \multirow[b]{2}{*}{ DIP rs3832406 } & & \multirow[t]{2}{*}{ Allele } & \multicolumn{2}{|c|}{ Passed } & \multicolumn{2}{|c|}{ Not Passed } & \multirow[t]{2}{*}{ GRR $^{1}(95 \% \mathrm{Cl})$} & \multirow[t]{2}{*}{ P-value } \\
\hline & & & $n$ & $\%$ & $n$ & $\%$ & & \\
\hline & Isolated CLP & 1 & 194 & 55.6 & 155 & 44.4 & $1.3(1.0,1.5)$ & 0.0372 \\
\hline & & 2 & 119 & 47.2 & 133 & 52.8 & $0.9(0.7,1.1)$ & 0.3781 \\
\hline & & 3 & 88 & 43.8 & 113 & 56.2 & $0.8(0.6,1.0)$ & 0.0786 \\
\hline & & Total & 401 & & 401 & & & \\
\hline & Multiple CLP & 1 & 216 & 56.5 & 166 & 43.5 & $1.3(1.1,1.6)$ & 0.0107 \\
\hline & & 2 & 128 & 46.5 & 147 & 53.5 & $0.9(0.7,1.1)$ & 0.2523 \\
\hline & & 3 & 92 & 42.8 & 123 & 57.2 & $0.7(0.6,1.0)$ & 0.0351 \\
\hline & & Total & 436 & & 436 & & & \\
\hline & Isolated CPO & 1 & 145 & 52.5 & 131 & 47.5 & $1.1(0.9,1.4)$ & 0.3996 \\
\hline & & 2 & 86 & 47.8 & 94 & 52.2 & $0.9(0.7,1.2)$ & 0.5511 \\
\hline & & 3 & 77 & 48.1 & 83 & 51.9 & $0.9(0.7,1.3)$ & 0.6353 \\
\hline & & Total & 308 & & 308 & & & \\
\hline & Multiple CPO & 1 & 188 & 52.2 & 172 & 47.8 & $1.1(0.9,1.3)$ & 0.3992 \\
\hline & & 2 & 115 & 48.9 & 120 & 51.1 & $1.0(0.7,1.2)$ & 0.7443 \\
\hline & & 3 & 101 & 47.4 & 112 & 52.6 & $0.9(0.7,1.2)$ & 0.4512 \\
\hline & & Total & 404 & & 404 & & & \\
\hline \multirow[t]{12}{*}{ SNP rs17080476 } & Isolated CLP & G & 132 & 54.3 & 111 & 45.7 & $1.2(0.9,1.5)$ & 0.1785 \\
\hline & & A & 111 & 45.7 & 132 & 54.3 & & \\
\hline & & Total & 243 & & 243 & & & \\
\hline & Multiple CLP & G & 144 & 54.3 & 121 & 45.7 & $1.2(0.9,1.5)$ & 0.1582 \\
\hline & & A & 121 & 45.7 & 144 & 54.3 & & \\
\hline & & Total & 265 & & 265 & & & \\
\hline & Isolated CPO & G & 87 & 50.6 & 85 & 49.4 & $1.0(0.8,1.4)$ & 0.8788 \\
\hline & & A & 85 & 49.4 & 87 & 50.6 & & \\
\hline & & Total & 172 & & 172 & & & \\
\hline & Multiple CPO & G & 119 & 50.9 & 115 & 49.1 & $1.0(0.8,1.3)$ & 0.7937 \\
\hline & & A & 115 & 49.1 & 119 & 50.9 & & \\
\hline & & Total & 234 & & 234 & & & \\
\hline
\end{tabular}

${ }^{1} \mathrm{GRR}=$ genotype relative risk

${ }^{2} \mathrm{Cl}=$ confidence interval

${ }^{3}$ Significant values are marked in bold. 
Table 3 Logistic regression analysis of case/controls and mother/controls for DIP rs3832406 and SNP rs17080476 in all cleft samples

\begin{tabular}{|c|c|c|c|c|c|c|c|c|}
\hline & \multirow[t]{2}{*}{ Polymorphism/Allele } & \multirow[t]{2}{*}{ Name } & \multicolumn{2}{|c|}{ Dominant } & \multicolumn{2}{|c|}{ Recessive } & \multicolumn{2}{|c|}{ Multiplicative } \\
\hline & & & $\operatorname{OR}^{1}\left(95 \% \mathrm{Cl}^{2}\right)$ & $p$-value & $\mathrm{OR}(95 \% \mathrm{Cl})$ & $\mathrm{p}$-value & OR $(95 \% \mathrm{Cl})$ & $p$-value \\
\hline \multirow[t]{8}{*}{ Isolated CLP } & DIP Allele 1 & Case-CTRL & $1.1(0.8,1.5)$ & 0.6159 & $1(0.8,1.3)$ & 0.8468 & $1(0.9,1.2)$ & 0.7022 \\
\hline & & Mother-CTRL & $0.9(0.6,1.2)$ & 0.3917 & $0.9(0.7,1.1)$ & 0.4774 & $0.9(0.8,1.1)$ & 0.3476 \\
\hline & DIP Allele 2 & Case-CTRL & $1.1(0.9,1.4)$ & 0.3358 & $0.8(0.5,1.4)$ & 0.4926 & $1.1(0.9,1.3)$ & 0.5534 \\
\hline & & Mother-CTRL & $1.1(0.9,1.4)$ & 0.2363 & $1.2(0.7,2)$ & 0.5077 & $1.1(0.9,1.4)$ & 0.2176 \\
\hline & DIP Allele 3 & Case-CTRL & $0.9(0.7,1.1)$ & 0.1928 & $1(0.5,2)$ & 0.9158 & $0.9(0.7,1.1)$ & 0.2349 \\
\hline & & Mother-CTRL & $1(0.8,1.3)$ & 0.9044 & $0.7(0.3,1.5)$ & 0.3311 & $1(0.8,1.2)$ & 0.8726 \\
\hline & SNP & Case-CTRL & $1(0.6,1.8)$ & 0.9798 & $0.9(0.7,1.1)$ & 0.1816 & $0.9(0.7,1.1)$ & 0.2494 \\
\hline & & Mother-CTRL & $1.3(0.7,2.5)$ & 0.4286 & $0.9(0.7,1.1)$ & 0.2382 & $0.9(0.8,1.1)$ & 0.4336 \\
\hline \multirow[t]{8}{*}{ Multiple CLP } & DIP Allele 1 & Case-CTRL & $1(0.7,1.4)$ & 0.9697 & $1(0.8,1.2)$ & 0.9333 & $1(0.8,1.2)$ & 0.9358 \\
\hline & & Mother-CTRL & $0.8(0.6,1.2)$ & 0.2857 & $0.9(0.7,1.2)$ & 0.4737 & $0.9(0.8,1.1)$ & 0.2955 \\
\hline & DIP Allele 2 & Case-CTRL & $1.1(0.9,1.4)$ & 0.258 & $0.9(0.5,1.6)$ & 0.6969 & $1.1(0.9,1.3)$ & 0.4046 \\
\hline & & Mother-CTRL & $1.1(0.9,1.4)$ & 0.2396 & $1.3(0.8,2.2)$ & 0.3264 & $1.1(0.9,1.4)$ & 0.1809 \\
\hline & DIP Allele 3 & Case-CTRL & $0.9(0.7,1.1)$ & 0.323 & $1(0.5,2.2)$ & 0.9053 & $0.9(0.7,1.1)$ & 0.3998 \\
\hline & & Mother-CTRL & $1(0.8,1.3)$ & 0.9303 & $0.7(0.3,1.7)$ & 0.4316 & $1(0.8,1.2)$ & 0.8883 \\
\hline & SNP & Case-CTRL & $1(0.5,1.8)$ & 0.9538 & $0.9(0.7,1.1)$ & 0.2786 & $0.9(0.8,1.1)$ & 0.3381 \\
\hline & & Mother-CTRL & $1.2(0.6,2.3)$ & 0.5906 & $0.9(0.7,1.1)$ & 0.2905 & $0.9(0.8,1.1)$ & 0.4526 \\
\hline \multirow[t]{8}{*}{ Isolated CPO } & DIP Allele 1 & Case-CTRL & $1(0.7,1.4)$ & 0.9498 & $1(0.8,1.2)$ & 0.6933 & $1(0.8,1.2)$ & 0.7915 \\
\hline & & Mother-CTRL & $0.9(0.6,1.2)$ & 0.3981 & $0.8(0.6,1)$ & 0.0708 & $0.9(0.7,1)$ & 0.0808 \\
\hline & DIP Allele 2 & Case-CTRL & $1(0.8,1.3)$ & 0.8703 & $0.5(0.2,1.1)$ & 0.0749 & $1(0.8,1.2)$ & 0.6497 \\
\hline & & Mother-CTRL & $1(0.8,1.3)$ & 0.7614 & $1.1(0.6,1.9)$ & 0.798 & $1(0.8,1.3)$ & 0.7284 \\
\hline & DIP Allele 3 & Case-CTRL & $1.1(0.9,1.4)$ & 0.3873 & $1.1(0.5,2.4)$ & 0.7843 & $1.1(0.9,1.4)$ & 0.3963 \\
\hline & & Mother-CTRL & $1.3(1,1.7)$ & $0.0431^{3}$ & $1.1(0.5,2.4)$ & 0.7368 & $1.2(1,1.5)$ & 0.0576 \\
\hline & SNP & Case-CTRL & $0.8(0.4,1.4)$ & 0.4111 & $1(0.8,1.3)$ & 0.7454 & $1(0.8,1.2)$ & 1 \\
\hline & & Mother-CTRL & $0.8(0.4,1.5)$ & 0.4739 & $1(0.8,1.3)$ & 0.8894 & $1(0.8,1.2)$ & 0.7186 \\
\hline \multirow[t]{8}{*}{ Multiple CPO } & DIP Allele 1 & Case-CTRL & $1(0.7,1.5)$ & 0.9335 & $1(0.8,1.3)$ & 0.9081 & $1(0.8,1.2)$ & 0.8998 \\
\hline & & Mother-CTRL & $0.8(0.6,1.2)$ & 0.3735 & $0.8(0.7,1.1)$ & 0.2065 & $0.9(0.7,1.1)$ & 0.1723 \\
\hline & DIP Allele 2 & Case-CTRL & $1(0.8,1.3)$ & 0.8253 & $0.5(0.2,1.2)$ & 0.1285 & $1(0.8,1.2)$ & 0.7474 \\
\hline & & Mother-CTRL & $1(0.8,1.3)$ & 0.824 & $1(0.5,1.9)$ & 0.9076 & $1(0.8,1.3)$ & 0.882 \\
\hline & DIP Allele 3 & Case-CTRL & $1.1(0.8,1.4)$ & 0.5704 & $1(0.4,2.5)$ & 0.9392 & $1.1(0.8,1.4)$ & 0.598 \\
\hline & & Mother-CTRL & $1.2(0.9,1.6)$ & 0.1179 & $1.4(0.6,3.1)$ & 0.4179 & $1.2(1,1.6)$ & 0.1044 \\
\hline & SNP & Case-CTRL & $0.9(0.5,1.7)$ & 0.7393 & $1(0.8,1.3)$ & 0.9235 & $1(0.8,1.2)$ & 0.847 \\
\hline & & Mother-CTRL & $0.7(0.4,1.4)$ & 0.3247 & $1(0.8,1.3)$ & 0.9406 & $1(0.8,1.2)$ & 0.6925 \\
\hline
\end{tabular}

${ }^{1} \mathrm{OR}=$ odds ratio

${ }^{2} \mathrm{Cl}=$ confidence interval

${ }^{3}$ Significant values are marked in bold.

of cleft in an Irish cohort. The main limitation of our study would be sample size and the uncorrected p-values do indicate a possible association between the rs3832406 DIP and risk of CLP. However, we suggest further screening of rs3832406 DIP in a larger cohort and describe a new assay that will facilitate this. We have demonstrated that the modified Melting Curve Analysis developed for DIP rs3832406 could be a valid alternative to capillary electrophoresis for the genotyping of multiple allele deletion/insertion polymorphisms and can be employed by any laboratory with a Real-Time PCR instrument with melting curve capacity.

\section{Abbreviations}

CLP: Cleft lip with or without cleft palate; CPO: Cleft palate only; DIP: Deletion/insertion polymorphism; HWE: Hardy-Weinberg equilibrium; LD: Linkage disequilibrium; MTHFD1: Methylenetetrahydrofolate 
dehydrogenase (NADP + dependent); MTHFD1L: Methylenetetrahydrofolate dehydrogenase (NADP + dependent) 1-like;

MTHFR: Methylenetetrahydrofolate reductase; MTR: Methionine synthase; MTHFS: Methenyltetrahydrofolate synthetase; NTD: Neural tube defect; SNP: Single nucleotide polymorphism; TDT: Transmission disequilibrium test.

\section{Competing interest}

The authors declare that they have no competing interests.

\section{Acknowledgements}

This work was supported by the IRCSET Embark initiative. The authors sincerely thank all the patients and families who participated in the study, the Cleft Lip and Palate Association of Ireland, and the Dublin Cleft Centre team. Recruitment of the Irish cleft cohort was supported by the Intramural Research Program of the Eunice Kennedy Shriver National Institute of Child Health and Human Development and the Health Research Board of Ireland.

\section{Author details}

${ }^{1}$ Nutritional Genomics Group, School of Biotechnology, Dublin City University, Dublin, Ireland. ${ }^{2}$ School of Medicine, Trinity College Dublin, Dublin 2, Ireland. ${ }^{3}$ Child Health Epidemiology Unit, Health Research Board, Dublin, Ireland. ${ }^{4}$ Department of Health and Human Services, Eunice Kennedy Shriver National Institute of Health, Bethesda, MD, USA. ${ }^{5}$ School of Immunology \& Biochemistry, Trinity College Dublin, Dublin 2, Ireland. ${ }^{6}$ Molecular Pathogenesis Section, Genome Technology Branch, National Human Genome Research Institute, Bethesda, MD, USA.

\section{Authors' contributions}

SM designed and carried out the genotyping assays, performed data analysis and drafted the paper. AM participated in the study design and execution, and commented on the manuscript. PK participated in the study design. JM participated in the study design and commented on the manuscript. JS participated in the study design. JT performed the statistical analyses. FP participated in the study design and commented on the manuscript. LB participated in the study design. APM participated in genotyping assay and study design, data interpretation and drafting of the paper. All authors read and approved the final manuscript.

Received: 19 December 2011 Accepted: 20 April 2012 Published: 20 April 2012

\section{References}

1. Boyles AL, Wilcox AJ, Taylor JA, Meyer K, Fredriksen A, Ueland PM, Drevon $C A$, Vollset SE, Lie RT: Folate and one-carbon metabolism gene polymorphisms and their associations with oral facial clefts. Am J Med Genet A 2008, 146:440-449.

2. van Rooij IA, Ocke MC, Straatman H, Zeilhuis GA, Merkus HM Steegers-Theunissen RP: Periconceptional folate intake by supplement and food reduces the risk of nonsyndromic cleft lip with or without cleft palate. Prev Med 2004, 39:689-694.

3. Wehby GL, Murray JC: Folic acid and orofacial clefts: a review of the evidence. Oral Dis 2010, 16:11-19.

4. Blanton SH, Henry RR, Yuan Q, Mulliken JB, Stal S, Finnell RH, Hecht JT: Folate Pathway and Nonsyndromic Cleft Lip and Palate. Birth Defects Res A ClinMolTeratol 2011, 91:50-60

5. Wilcox A, Lie RT, Solvoll K, Taylor J, McConnaughey DR, Abyholm F, Vindenes $\mathrm{H}$, Vollset SE, Drevon CA: Folic acid supplements and risk of facial clefts: national population based case-control study. BMJ 2007, 334:464.

6. Ray JG, Meier C, Vermeulen MJ, Wyatt PR, Cole DE: Association between folic acid food fortification and congenital orofacial clefts. J Pediatr 2003, 143:805-807.

7. Wehby G, Cassell CH: The impact of orofacial clefts on quality of life and healthcare use and costs. Oral Dis 2010, 16:3-10.

8. Shaw GM, Rozen R, Finnell RH, Todoroff K, Lammer EJ: Infant C677T mutation in MTHFR, maternal periconceptional vitamin use, and cleft lip. Am J Med Genet 1998, 80:196-198.

9. Martinelli M, Scapoli L, Pezzetti F, Carinci F, Carinci P, Stabellini G, Bisceglia L, Gombos F, Tognon M: C677T variant form at the MTHFR gene and CL/P: a risk factor for mothers? Am J Med Genet 2001, 98:357-360.
10. Blanton SH, Patel S, Hecht JT, Mulliken JB: MTHFR is not a risk factor in the development of isolated nonsyndromic cleft lip and palate. Am J Med Genet 2002, 110:404-405

11. Prescott NJ, Winter RM, Malcolm S: Maternal MTHFR genotype contributes to the risk of non-syndromic cleft lip and palate. J Med Genet 2002, 39:368-369.

12. Jugessur A, Wilcox AJ, Lie RT, Murray JC, Taylor JA, Ulvik A, Drevon CA, Vindenes HA, Abyholm FE: Exploring the effects of methylenetetrahydrofolate reductase gene variants C677T and A1298C on the risk of orofacial clefts in 261 Norwegian case-parent triads. Am J Epidemiol 2003, 157:1083-1091.

13. Shotelersuk V, Ittiwut C, Siriwan P, Angspatt A: Maternal 677CT/1298 AC genotype of the MTHFR gene as a risk factor for cleft lip. J Med Genet 2003, 40:e64.

14. van Rooij IA, Vermeij-Keers C, Kluijtmans LA, Ocke MC, Zielhuis GA Goorhuis-Brouwer SM, van der Biezen JJ, Kuijpers-Jagtman AM, SteegersTheunissen RP: Does the interaction between maternal folate intake and the methylenetetrahydrofolate reductase polymorphisms affect the risk of cleft lip with or without cleft palate? Am J Epidemiol 2003, 157:583-591.

15. Vieira AR, Murray JC, Trembath D, Orioli IM, Castilla EE, Cooper ME, Marazita ML, Lennon-Graham F, Speer M: Studies of reduced folate carrier 1 (RFC1) A80G and 5,10-methylenetetrahydrofolate reductase (MTHFR) C677T polymorphisms with neural tube and orofacial cleft defects. Am J Med Genet A 2005, 135:220-223.

16. Mills JL, Molloy AM, Parle-McDermott A, Troendle JF, Brody LC, Conley MR, Cox C, Pangilinan F, Orr DJA, Earley M, McKiernan E, Lynn EC, Doyle A, Scott $J \mathrm{M}$, Kirke PN: Folate-related gene polymorphisms as risk factors for cleft lip and cleft palate. Birth Defects Res A Clin Mol Teratol 2008, 82:636-643.

17. Mostowska A, Hozyasz KK, Wojcicki P, Dziegelewska M, Jagodzinski PP: Associations of folate and choline metabolism gene polymorphisms with orofacial clefts. J Med Genet 2010, 47:809-815.

18. Martinelli M, Scapoli L, Palmieri A, Pezzetti F, Baciliero U, Padula E, Carinci P, Morselli PG, Carinci F: Study of four genes belonging to the folate pathway: transcobalamin 2 is involved in the onset of non-syndromic cleft lip with or without cleft palate. Hum Mutat 2006, 27:294.

19. Bufalino A, Ribeiro-Paranaíba LM, Nascimento-de-Aquino S, Martelli-Júnior $H$, Oliveira-Swerts MS, Coletta RD: Maternal polymorphisms in folic acid metabolic genes are associated with nonsyndromic cleft lip and/or palate in the Brazilian population. Birth Defects Res A Clin Mol Teratol 2010, 88:980-986.

20. Parle-McDermott A, Pangilinan F, O'Brien KK, Mills JL, Magee AM, Troendle J, Sutton M, Scott JM, Kirke PN, Molloy AM, Brody LC: A common variant in MTHFD1L is associated with neural tube defects and mRNA splicing efficiency. Hum Mutat 2009, 30:1650-1656.

21. Samani F, Erdmann J, Hall AS, Hengstenberg C, Mangino M, Mayer B, Dixon RJ, Meitinger T, Braund P, Wichmann H-E, Barrett JH, König IR, Stevens SE, Szymczak S, Tregouet D-A, lles MM, Pahlke F, Pollard H, Lieb W, Cambien F, Fischer M, Ouwehand W, Blankenberg S, Balmforth A, Baessler A, Ball SG, Strom TM, Brænne I, Gieger C, Deloukas P, Tobin MD, Ziegler A, Thompson JR, Schunkert H, for the WTCCC and the Cardiogenics Consortium: Genomewide association analysis of coronary artery disease. N Engl J Med 2007, 357:443-453.

22. Bressler J, Folsom AR, Couper DJ, Volcik KA, Boerwinkle E: Genetic Variants Identified in a European Genome-Wide Association Study That Were Found to Predict Incident Coronary Heart Disease in the Atherosclerosis Risk in Communities Study. Am J Epidemiol 2010, 171:14-23.

23. Naj AC, Beecham GW, Martin ER, Gallins PJ, Powell EH, Konidari I, Whitehead PL, Cai G, Haroutunian V, Scott WK, Vance JM, Slifer MA, Gwirtsman HE, Gilbert JR, Haines JL, Buxbaum JD, Pericak-Vance MA: Dementia Revealed: Novel Chromosome 6 Locus for Late-Onset Alzheimer Disease Provides Genetic Evidence for Folate-Pathway Abnormalities. PLOS Genet 2010, 6:e1001130.

24. Sugiura $T$, Nagano $Y$, Tatsuya Inoue $T$, Hirotani $K$ : A novel mitochondrial C1-tetrahydrofolate synthetase is upregulated in human colon adenocarcinoma. Biochem Biophys Res Commun 2004, 315:204-211.

25. Prasannan P, Appling DR: Human mitochondrial C1-tetrahydrofolate synthase: Submitochondrial localization of the full-length enzyme and characterization of a short isoforms. Arch Biochem Biophys 2009, 481:86-93.

26. Prasannan P, Pike S, Peng K, Shane B, Appling DR: Human mitochondrial C1-tetrahydrofolate synthase: gene structure, tissue distribution of the mRNA, and immunolocalization in Chinese hamster ovary calls. J Biol Chem 2003, 278:43178-43187.

27. Parle-McDermott A, Kirke PN, Mills JL, Molloy AM, Cox C, O'Leary VB, Pangilinan F, Conley M, Cleary L, Brody LC, Scott JM: Confirmation of the 
R653Q polymorphism of the trifunctional C1-synthase enzyme as a maternal risk for neural tube defects in the Irish population. Eur J Hum Genet 2006, 14:768-772.

28. Spielman S, McGinnis E, Ewens J: Transmission test for linkage disequilibrium: the insulin gene region and insulin-dependent diabetes mellitus (IDDM). AmJ Hum Genet 1993, 52:506-516.

29. Troendle JF, Mills JL: Correction for multiplicity in Genetic Association Studies of Triads: the Permutational TDT. Ann Hum Genet 2011, 75:284-291.

doi:10.1186/1471-2350-13-29

Cite this article as: Minguzzi et al:: Genotyping of a tri-allelic polymorphism by a novel melting curve assay in MTHFD1L: an association study of nonsyndromic Cleft in Ireland. BMC Medical Genetics 2012 13:29

\section{Submit your next manuscript to BioMed Central and take full advantage of:}

- Convenient online submission

- Thorough peer review

- No space constraints or color figure charges

- Immediate publication on acceptance

- Inclusion in PubMed, CAS, Scopus and Google Scholar

- Research which is freely available for redistribution 